\title{
Clustering approach to detect mRNA-degradation patterns from DNA-microarray gene-expression data
}

\author{
Susanne Motameny ${ }^{1}$, Röbbe Wünschiers ${ }^{2 *}$ \\ ${ }^{1}$ Cologne Center for Genomics, Cologne University, Zülpicher Strasse 47, 50674 Cologne, Germany \\ ${ }^{2}$ University of Applied Sciences Mittweida, Technikumplatz 17, 09648 Mittweida, Germany \\ *Corresponding author \\ roebbe.wuenschiers@hs-mittweida.de
}

Received: 15 October 2012; accepted: 2 November 2012; published online: 12 November 2012.

This paper has no supplementary material.

\begin{abstract}
DNA-microarray based gene-expression analysis is based on hybridization events between messenger RNA (mRNA) and single stranded DNA probes. In oligo nucleotide DNA-microarrays the probes consist of approximately 20 to 80 nucleotides long DNA-molecules. Consequently, several unique probes perfectly matching each single open reading frame (ORF) of mono- or polycistronic mRNA are usually used. If these probes are distributed over the whole length of the mRNA molecule, information about mRNA-degradation patterns can be gathered with data clustering methods.

Here we report analysis of expression of 1107 open reading frames from the cyanobacterium Nostoc PCC 7120 . Each open reading frame was covered by 10 unique 25 nucleotides long probes and analyzed by 4 independent DNA-microarray experiments. Both the positional information and the absolute expression value for each probe were used to infer clusters of transcripts that show similar expression patterns. Hierarchical and fuzzy k-means clustering yielded comparable results. Our results suggest that several different mRNA-degradation mechanisms, specific for certain transcripts, work in concert.
\end{abstract}

Keywords: Bioinformatics, Computational Biology, DNA-Microarrays, Gene-Expression, mRNA-Degradation.

\section{Introduction}

In living organisms, information generally flows from DNA via mRNA to protein (Fig. 1).

Each protein is encoded by a gene, the expression of which is regulated by an upstream promoter region. The expression process is mediated by two steps: transcription of one (monocistronic transcript) or many (polycistronic transcript) genes to mRNA and translation of the mRNA to protein(s), respectively. As long as a mRNA molecule is present in the bacterial cell it will be translated to protein. In order to respond quickly to changing biotic or abiotic conditions, the expression process is regulated at different levels. Of major importance is the regulation of the amount of transcripts (mRNA-molecules) (Lackner and Bähler, 2008). Therefore, the transcription of genes is switched on and off or regulated up or down. These regulatory events can only take effect, if the corresponding mRNA is inactivated quickly.

One known and obvious process of transcript inactivation is mRNA-degradation, which has been analyzed intensively in the past (see, e.g. Carpousis et al., 1999; Garneau et al., 2007; Houseley and Tollervey, 2009; Kristoffersen et al., 2012). In Escherichia coli, mRNA-degradation is mediated by the combined action of endo- and exoribonucleases (Nierlich and Murakawa, 1996).

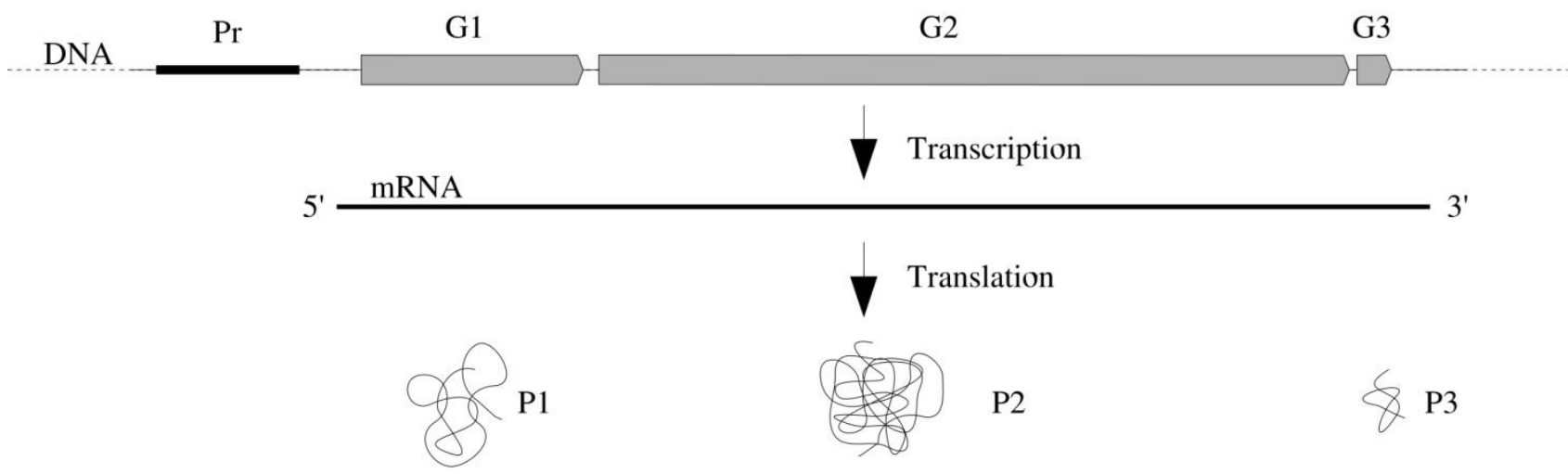

Fig. 1. Gene Expression - The linear sequence of four different nucleotides (A, C, T, G) on the DNA carries information. Defined stretches of DNA, genes $(\mathrm{G1}, \mathrm{G} 2, \mathrm{G3})$, encode for proteins $(\mathrm{P1}, \mathrm{P2}, \mathrm{P3})$. In bacteria, several genes are usually organized as operons and regulated by a common promoter $(\mathrm{Pr})$. 
More than 20 ribonucleases have been identified in this organism. Degradation initiates with an endoribonucleolytic cleavage followed by exoribonuclease digestion to generate 5'mononucleotides. The exoribonucleases PNPase and RNase II are key players for the 3' to 5' processive degradation, while the exoribonucleases RNase $\mathrm{R}$ is particularly important for removing mRNA fragments with extensive secondary structures (Cheng and Deutscher, 2005). The 5'-end dependent endonuclease RNase E catalyzes a 5' to 3' processive degradation (Mackie, 1998). Only RNase E and RNase P appear to be essential for growth since no knock-out mutant could be isolated (Donovan and Kushner, 1986). All components are organized as a large multiprotein complex, known as the RNA-degradosome. Genes encoding enzymes related to PNPase, RNase II, and RNase $\mathrm{R}$ can be found in the cyanobacterium Nostoc PCC 7120 as well.

Although transcript stability has been analyzed for some prokaryotes (Selinger et al., 2003) the variety of the corresponding mRNA-degradation pathways remain only partially characterized (Kaberdin et al., 2011). This initiated us to examine DNA-microarray based gene-expression data generated in our lab for mRNA-degradation patterns. In contrary to other DNA-microarray based studies (e.g. Selinger et al., 2003) we do not repress gene expression by application of transcriptional inhibitors but use data from one single timepoint. This has the advantage of an undisturbed data set at the cost of less resolution. Each open reading frame was covered by 10 unique probes and analyzed by 4 independent DNAmicroarray experiments. Both the positional information and the absolute expression value for each probe were used to infer clusters of transcripts that show similar expression patterns. Our results suggest that several different mRNA-degradation mechanisms, specific for certain transcripts, work in concert.

Based on mRNA degradation in E. Coli, three degradation patterns can be expected to appear in the expression data. These are illustrated in Fig. 2.
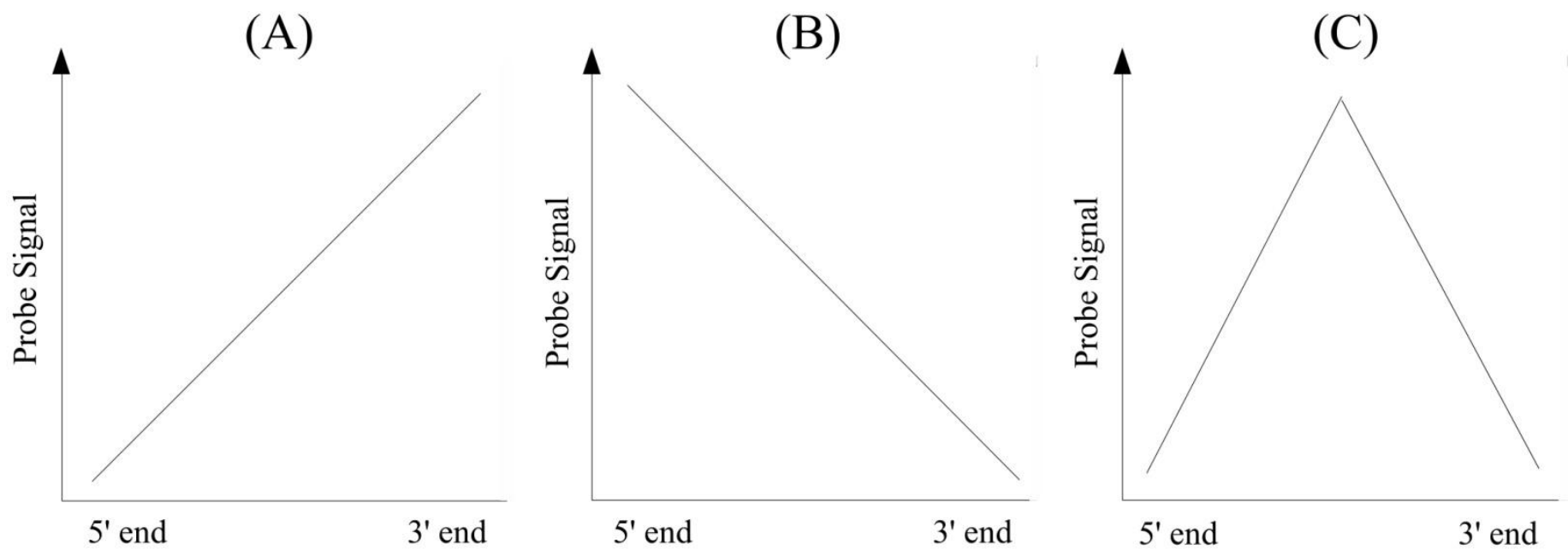

Fig. 2. Expected Degradation Patterns - (A) 5' to 3' degradation, (B) 3' to 5' degradation, (C) simultaneous degradation from 5' to 3' and 3' to 5'.

\section{Matherials and methods}

\subsection{Strain and Culture Conditions}

The cyanobacterium Nostoc sp. strain PCC 7120 (Nostoc PCC 7120; formerly Anabaena PCC 7120) was grown in either nitrogen fixing or non-nitrogen fixing conditions as previously described (Hansel et al., 2001).

\subsection{Preparation of Biotin Labeled, Fragmented cRNA}

Total RNA from Nostoc PCC 7120 was extracted as previously described (Axelsson and Lindblad, 2002). From 10 $\mu \mathrm{g}$ of total RNA, low molecular weight RNA, e.g. tRNA and 5S rRNA, was removed by size exclusion chromatography (MEGAclear kit, Ambion). To remove 16S and 23S rRNA, the MICROBExpress kit from Ambion was used. The remaining RNA was linearly amplified by a modified Eberwine protocol (Eberwine et al., 1992) as follows. If not differently stated, all enzymes and chemicals were purchased from Invitrogene.

First Strand Synthesis. The pelleted RNA from the previous mRNA enrichment steps was resuspended in $4.25 \mu \mathrm{l}$ water and mixed with $1 \mu \mathrm{l}$ of T7 random hexamers $(0.5 \mu \mathrm{g} / \mu \mathrm{l}$; 5'-GGC CAG TGA ATT GTA ATA CGA CTC ACT ATA GGG AGG CGG NNN NNN-3'). Following incubation at $70^{\circ} \mathrm{C}$ for $10 \mathrm{~min}, 4^{\circ} \mathrm{C}$ for $2 \mathrm{~min}$ and $23^{\circ} \mathrm{C}$ for $5 \mathrm{~min}, 3.75 \mu \mathrm{l}$ reaction mix $(2 \mu \mathrm{l} 5 \mathrm{x}$ first strand synthesis buffer, $1 \mu \mathrm{l} 0.1 \mathrm{M}$
DTT, $0.5 \mu 10 \mathrm{mM}$ dNTP mix, $0.25 \mu \mathrm{l} 40 \mathrm{U}$ RNase OUT and 200 U Superscript II polymerase) was added to the RNA/primer mix. First strand synthesis reaction was performed with the following temperature scheme: $37^{\circ} \mathrm{C}$ for 20 $\min , 42^{\circ} \mathrm{C}$ for $20 \mathrm{~min}, 50^{\circ} \mathrm{C}$ for $15 \mathrm{~min}, 55^{\circ} \mathrm{C}$ for $10 \mathrm{~min}$ and $65^{\circ} \mathrm{C}$ for $15 \mathrm{~min}$. After adding $0.5 \mu \mathrm{l}$ RNase $\mathrm{H}$, the reaction mix was incubated for another $30 \mathrm{~min}$ at $37^{\circ} \mathrm{C}$ and $2 \mathrm{~min}$ at $95^{\circ} \mathrm{C}$. Then, $1.7 \mu \mathrm{l}$ random hexamer primers $(0.3 \mu \mathrm{g} / \mu \mathrm{l})$ were added and the mix incubated for $10 \mathrm{~min}$ at $70^{\circ} \mathrm{C}$.

Second Strand Synthesis. The product of the first strand synthesis was mixed with $43.8 \mu \mathrm{l}$ water, $15 \mu \mathrm{l} 5 \mathrm{x}$ second strand synthesis buffer, $20 \mathrm{U}$ DNA polymerase I, $1.5 \mu 10 \mathrm{mM}$ dNTP and $1 \mathrm{U}$ RNaseH and incubated for $2 \mathrm{~h}$ at $16^{\circ} \mathrm{C}$. After addition of $10 \mathrm{U} \mathrm{T} 4 \mathrm{DNA}$-polymerase the reaction mix was first incubated at $16^{\circ} \mathrm{C}$ for $15 \mathrm{~min}$ and then at $70^{\circ} \mathrm{C}$ for $10 \mathrm{~min}$.

Isolation of ds-cDNA. Double stranded cDNA was isolated from the product of second strand synthesis according to standard procedures (Maniatis et al., 1982).

In vitro Transcription. The pelleted ds-cDNA was resuspended in $1.5 \mu \mathrm{l}$ water. The MEGAscript T7 kit (Ambion) was used for in vitro transcription. In addition to the standard nucleotides, $3.75 \mu 110 \mathrm{mM}$ Bio-16-CTP (NEN) and $3.75 \mu 175$ 
mM Bio-11-UTP (Roche) were added to the reaction mix. This led to the formation of biotinylated cRNA.

cRNA Isolation. The RNeasy kit (Qiagen) was applied for cRNA isolation. All steps were performed according to the manufacturer's instructions.

cRNA Fragmentation. For cRNA fragmentation $15 \mu \mathrm{g}$ cRNA was resuspended in $2.5 \mu \mathrm{l}$ water and $2.5 \mu \mathrm{l} 2 \mathrm{x}$ fragmentation buffer (5x stock: $200 \mathrm{mM}$ Tris, $150 \mathrm{mM} \mathrm{Mg-}$ acetate, $500 \mathrm{mM} \mathrm{K}$-acetate, $\mathrm{pH} 8.1$ ). The reaction mix was incubated for $5 \mathrm{~min}$ at $94^{\circ} \mathrm{C}$. The fragmentation reaction was performed immediately prior to hybridization.

\subsection{Oligonucleotide Probe Selection}

A unique Nostoc PCC 7120 probe set (as many 25mer probes per open reading frame (ORF) as possible) was calculated based on the full genome sequence (retrieved online from CyanoBase: http://www.kazusa.or.jp/cyanobase/Anabaena/index.html) using a combination of sequence uniqueness criteria and rules for selection of oligonucleotides likely to hybridize with high specificity and sensitivity. The selection criteria were essentially as described in Lockhart et al. (Lockhart et al., 1996) with modifications for the longer probes used here (25mers instead of 20mers). If available, 10 unique probes per ORF were used in the experiments.

\subsection{DNA-Microarray Production and In Situ Oligo \\ Nucleotide Synthesis}

Light-activated in situ oligonucleotide synthesis was performed essentially as described by Singh-Gasson et al. (Singh-Gasson et al., 1999) using a digital micromirror device (Güimil et al., 2003). The synthesis was performed within the geniom one device (Febit AG, Heidelberg, Germany) on an activated three-dimensional reaction carrier consisting of a glass-silica-glass sandwich (DNA processor). Four individually accessible microchannels (referred to as arrays) etched into the silica layer of the DNA processor are connected to the microfluidic system of the geniom device. Using standard DNA synthesis reagents and $3 \hat{\mathrm{A}}^{\prime}$-phosphoramidites with a photolabile protecting group (Beier and Hoheisel, 2000; Hasan et al., 1997), oligonucleotides were synthesized in parallel in all four translucent arrays of one reaction carrier. Prior to synthesis, the glass surface was activated by coating with a silane-bound spacer. The probe sets synthesized within the four arrays may be the same but also can be different on all arrays.

\subsection{Hybridization}

Hybridization was performed with $7.5 \mu \mathrm{g}$ fragmented cRNA (see above) in a final volume of $10 \mu \mathrm{l}$. Hybridization solutions contained $100 \mathrm{mM}$ MES ( $\mathrm{pH}$ 6.6), 0.9 M NaCl, 20 $\mathrm{mM}$ EDTA and $0.01 \%(\mathrm{v} / \mathrm{v})$ Tween 20 . In addition, the solutions contained $0.1 \mathrm{mg} / \mathrm{ml}$ sonicated herring sperm DNA and $0.5 \mathrm{mg} / \mathrm{ml}$ BSA. RNA samples were heated in the hybridization solution to $95^{\circ} \mathrm{C}$ for 3 min followed by $45^{\circ} \mathrm{C}$ for 3 min before being placed in an array which had been prehybridized for $15 \mathrm{~min}$ with $1 \%(\mathrm{w} / \mathrm{v}) \mathrm{BSA}$ in hybridization solution at RT. Hybridizations were carried out at $45^{\circ} \mathrm{C}$ for 16 h. After removing the hybridization solutions, arrays were first washed with non-stringent buffer $(0.005 \%$ (v/v) Triton X-100 in $6 \mathrm{x} \mathrm{SSPE}$ ) for $20 \mathrm{~min}$ at $25^{\circ} \mathrm{C}$ and subsequently with stringent buffer $(0.005 \%$ (v/v) Triton X-100 in $0.5 \times$ SSPE) for $20 \mathrm{~min}$ at $45^{\circ} \mathrm{C}$. After washing, the hybridized RNA was fluorescence-stained by incubating with $10 \mu \mathrm{g} / \mathrm{ml}$ streptavidinphycoerythrin and $2 \mu \mathrm{g} / \mu \mathrm{l} \mathrm{BSA}$ in $6 \times \mathrm{SSPE}$ at $25^{\circ} \mathrm{C}$ for 15 min. Unbound streptavidin-phycoerythrin was removed by washing with non-stringent buffer for $20 \mathrm{~min}$ at $25^{\circ} \mathrm{C}$. Hybridizations were not performed competitive on one DNA processor but separated with one condition per DNA processor.

\subsection{Detection \& Raw Data Generation}

The CCD-camera based fluorescence detection system, equipped with a $\mathrm{Cy} 3$ filter set, integrated into the geniom one automate was used. 36 pixels per spot were available for data analysis.

Processing of raw data, including background correction, array to array normalization and determination of gene expression levels, as well as calculation of fold-change values were performed as described before (Zhou and Abagyan, 2002). All steps were carried out using the PROP algorithm of the geniom application software which is based on the MOID algorithm (Zhou and Abagyan, 2002).

Background correction is based on probes with no corresponding mRNA target and the average of the lowest $5 \%$ expressed genes. Data normalization is based on iteratively correcting the raw data on non-regulated genes (fold-changes less than \pm 2 ). In a comparative study of Saccharomyces cerevisiae gene expression with three independent techniques (i.e., Affymetrix GeneChips, geniom one microarrays, and cDNA microarrays) it was previously shown that expression fold changes with values greater than \pm 1.5 are significant for the geniom one technology applied here (Baum et al., 2003). Thus, genes with fold changes between -1.5 and 1.5 can be considered to be non-regulated. In our study we extend the rule such that the upper or lower bound must be greater than \pm 2 for upregulated and downregulated genes, respectively. Furthermore, this rule must be fulfilled for all independent experiments.

\subsection{Data Filtering}

In order to investigate mRNA-degradation it is necessary that the probes are positioned along the whole length of the transcript. Therefore, only such genes were chosen which have a probe situated within the first and last 50 bases of their transcript. 199 genes of the 1107 measured probe sets satisfy this condition and were selected for subsequent analysis. 23 of these genes showed different probe rankings on different arrays and were therefore excluded from further analysis. There are many more effects other than mRNA-degradation that influence the measured probe-transcript hybridization strength, which are not yet fully understood (Rule et al., 2009). However, it is known that the GC-content of a probe influences the strength of the hybridization and thus the expression value. To account for this effect, all genes were removed whose expression profiles showed a high Pearson's correlation (greater than 0.4) to the GC-contents of the probes. In this step, another 43 genes were excluded from further analysis. The expression values of the remaining 133 genes were logarithmized and then scaled to have mean zero and unit variance. The last step of data filtering included the removal of outliers. Outliers were defined as genes whose scaled expression profiles were dominated by a peak at a single probe. 46 genes with a Pearson's correlation higher than 0.7 with a single-peaked profile were removed.

After the filtering procedure, scaled probe profiles of 87 genes remained and were used for further analysis. 
S.Motameny and R.Wünschiers

\subsection{Clustering}

Two clustering methods were applied to the filtered data: a hierarchical clustering using the GeneCluster and TreeView software from M. Eisen (Eisen et al., 1998) and fuzzy k-means (see e.g. Kruse et al., 1999), which we implemented in MATLAB. The average linkage method was chosen for hierarchical clustering, using the uncentered Pearson correlation as a similarity measure. Fuzzy k-means has been reported to be a useful method to uncover clusters in gene expression data (Gasch and Eisen, 2002). The fuzzy approach has several advantages over common hard clustering methods. It is able to detect overlapping clusters by assigning membership degrees to the genes. This means that every gene can belong to several clusters at different degrees. Another advantage is that by setting a membership cutoff, one can extract the genes which are most typical for a cluster. For the fuzzy k-means method we chose the number of clusters to be 18 and a fuzzyfier value of 1.2. The distance measure used was the euclidean distance.

\section{Results and discussion}

\subsection{Probe Set Ranking}

In order to test whether our data set is stable enough to provide an insight into mRNA-degradation, we tested if the ranking of the probes for each ORF was the same for all four independent hybridizations. Therefore, all ORF-specific probes were numbered according to their position from the 5 ' - to the 3 '-end. Then, the probe numbers were ordered by the expression level (Fig. 3). The resulting order was compared for all four independent hybridizations. 994 of all 1107 analyzed ORFs passed this test. Out of these, another 907 expression datasets were removed as described in 2.7.
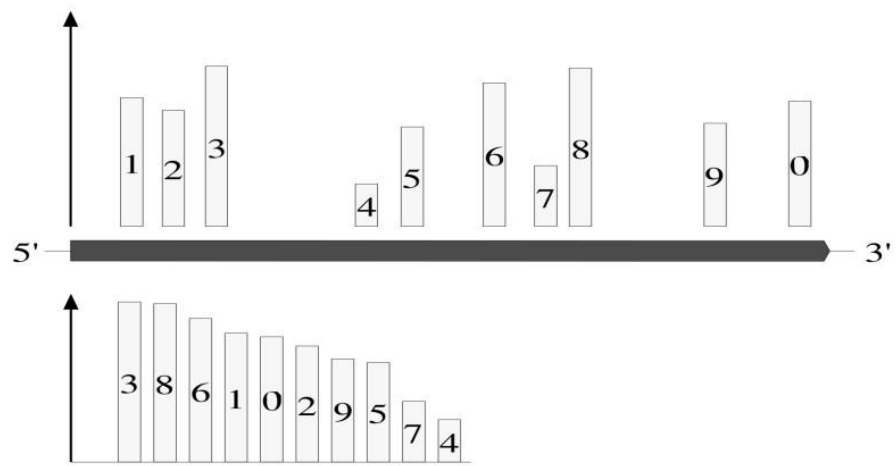

Fig. 3. Probe Set Ranking - Schematic outline for the method used to rank probe sets for each gene for all four DNAmicroarrays by their expression data. $89.8 \%$ probe sets showed the same ranking in all four individual hybridization reactions.

\subsection{Probe Position Dependent Expression Data}

As stated above, mRNA-degradation is mediated by the combined action of endo- and exoribonucleases. Up-to-now, mRNA-degradation from the 3'- to 5'-end or vice versa can be discriminated. Other processes like degradation from both ends simultaneously or any other patterns have not been described yet. Under the assumption that the majority of all transcripts are degraded by the same mechanism, all ORF-specific probe sets should yield similar expression patterns. This was analyzed by testing for all ORFs if the expression value of probe $n-1$ is smaller or larger than the expression value of probe $n$. The results are shown in a matrix in Fig. 4. The number of cases where an upstream probe shows a lower expression value are counted in the upper triangle and vice versa.

\begin{tabular}{c|cccccccccc} 
& $\mathbf{1}$ & $\mathbf{2}$ & $\mathbf{3}$ & $\mathbf{4}$ & $\mathbf{5}$ & $\mathbf{6}$ & $\mathbf{7}$ & $\mathbf{8}$ & $\mathbf{9}$ & $\mathbf{0}$ \\
\hline $\mathbf{1}$ & - & $\mathbf{5 5 7}$ & 559 & 589 & 584 & 572 & 588 & 544 & 556 & 591 \\
$\mathbf{2}$ & 550 & - & 549 & 588 & 594 & 577 & 573 & 562 & 561 & 561 \\
$\mathbf{3}$ & 548 & 558 & - & 594 & 589 & 585 & 586 & 548 & 564 & 578 \\
$\mathbf{4}$ & 518 & 518 & 513 & - & 559 & 537 & 545 & 533 & 516 & 545 \\
$\mathbf{5}$ & 523 & 513 & 518 & 548 & - & 537 & 565 & 528 & 526 & 546 \\
$\mathbf{6}$ & 535 & 530 & 522 & 570 & 570 & - & 551 & 552 & 523 & 563 \\
$\mathbf{7}$ & 519 & 534 & 521 & 562 & 542 & 556 & - & 544 & 529 & 524 \\
$\mathbf{8}$ & 563 & 545 & 559 & 574 & 579 & 555 & 563 & - & 550 & 546 \\
$\mathbf{9}$ & 551 & 546 & 543 & 590 & 581 & 584 & 578 & 557 & - & 570 \\
$\mathbf{0}$ & 516 & 546 & 529 & 562 & 561 & 544 & 582 & 561 & 537 & -
\end{tabular}

Fig. 4. Probe Position Dependent Expression Data - For all genes with 10 unique probes the probes were ordered from the 5'- to 3'end (probes 1 to 0 ). The number of cases where an upstream probe shows a lower (upper triangle) or higher (lower triangle) expression value than the corresponding downstream probe are shown.

If there was a common pattern from either side for the majority of the ORFs, one should observe a clear difference in the upper and the lower triangles. This is not the case, indicating that mRNA-degradation underlies no common mechanism in Nostoc PCC 7120. Fig. 5 shows a graphical representation of the data from Fig. 4. Here it becomes clear that mRNA-degradation underlies no common mechanism in Nostoc PCC 7120.

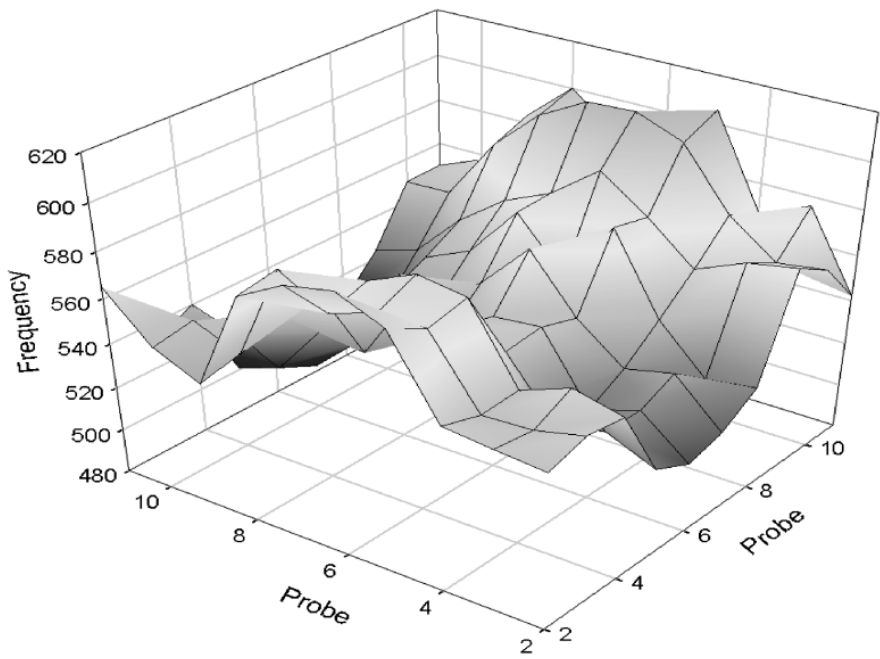

Fig.5. Probe Position Dependent Expression Data - Graphical presentation of the data shown in Fig. 4.

\subsection{Clustering}

\subsubsection{Clusters with Identical Probe Patterns}

Initially, we extracted all probe sets that showed the same probe distribution patterns. We found four such clusters. 18 members of these clusters are annotated tranposases whereas 2 members are hypothetical proteins. Excluding the latter, all clusters can be explained by ORF sequence and consequently probe sequence similarity (Fig. 6).

To our surprise, these transposases are expressed at a rather high level, with equal expression levels and profiles within each cluster (Fig. 7). Transposons, also known as jumping genes, can spread themselves in a genome by a kind of copypaste mechanism, catalyzed by a transposase enzyme for which they encode. If transposons copy themselves into a functional ORF or regulatory region, this gene commonly gets inactivated.

With our method we can discriminate four different transposon classes. Interestingly, each cluster is not only 
specified by a common probe pattern and similar sequences but also by similar expression values.

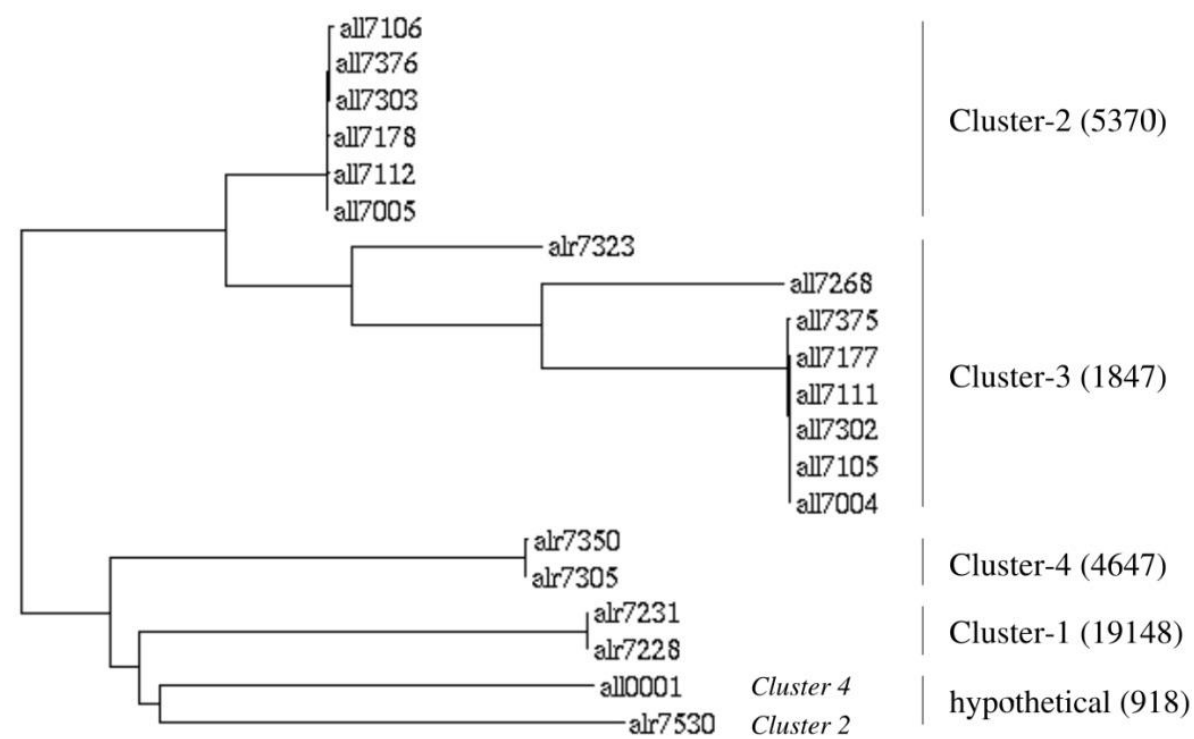

Fig. 6. Sequence Distance Tree - This tree represents a protein sequence based distance tree of all sequences that are members of clusters with identical probe patterns. For the two hypothetical protein sequences the cluster membership is indicated. Numbers in parenthesis give the mean expression value of the members of the cluster.
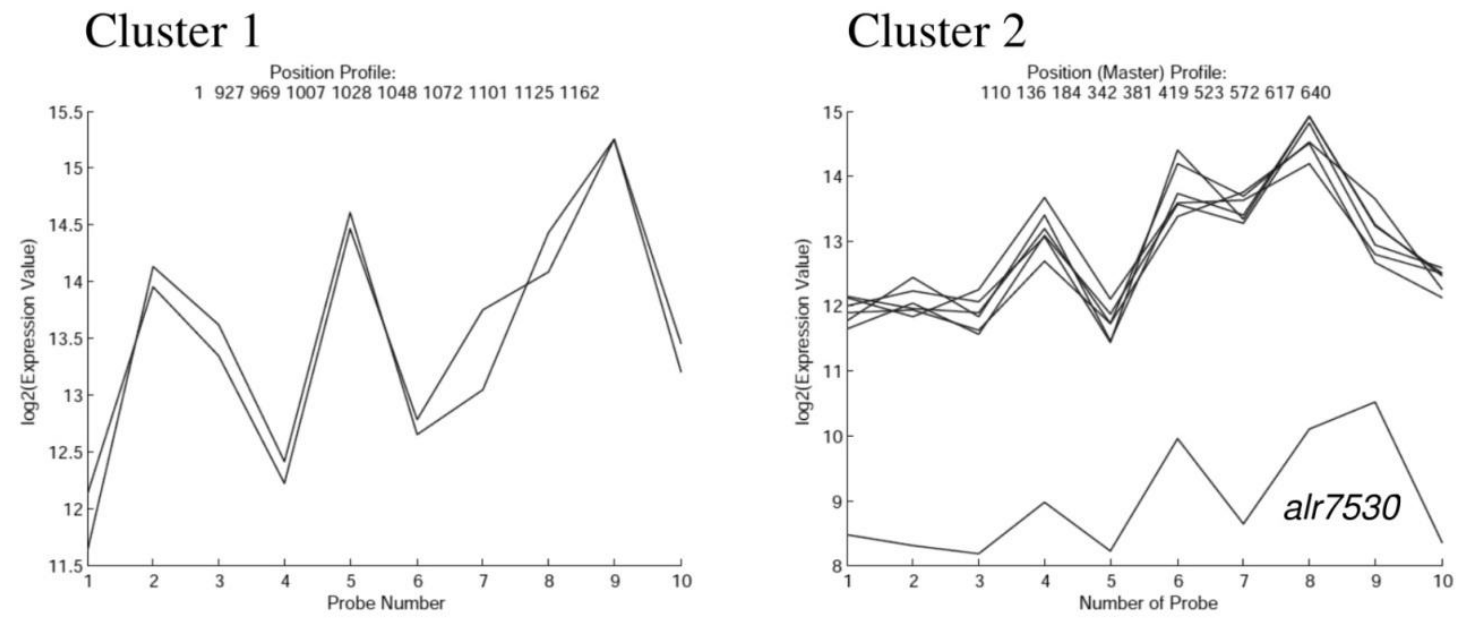

\section{Cluster 3}

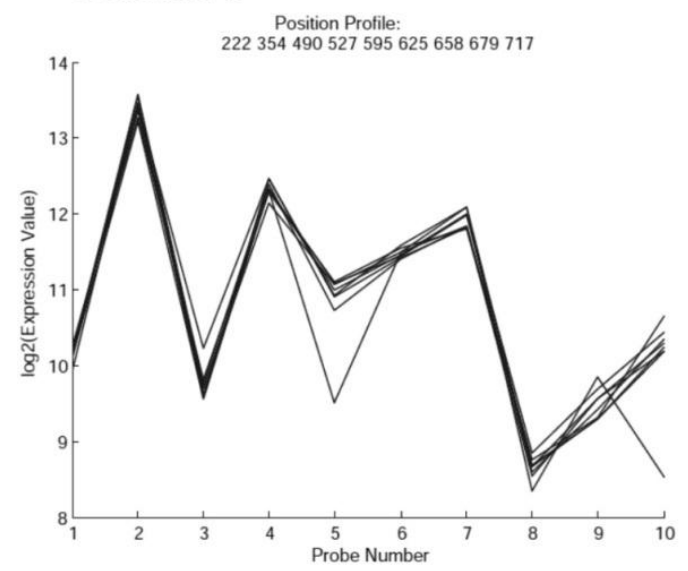

Cluster 4

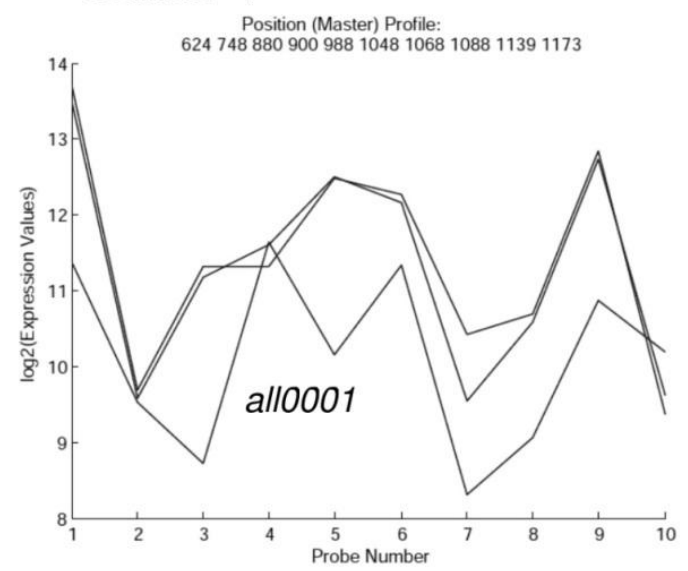

Fig. 7. Gene Expression - Clusters with very similar probe patterns. Outliers are identified by their gene ID. 

Fig. 9.

\subsubsection{Fuzzy K-Means}

The clusters produced by the fuzzy k-means clustering are depicted in (Fig.8). Together with the cluster identifier, the number of genes within each cluster is given. The membership cutoff was set to $70 \%$.

Clusters C5, C9, C14, and C16 show an increase of probe expression values from the 5'- to the 3'-end of the transcript. This corresponds to the assumption that a degradation mechanism is present which progresses from the 5'- to the 3'end. Cluster $\mathrm{C} 17$ shows an opposite pattern, with probe expression values decreasing towards the 3 '-end. This suggests a second mechanism of degradation working from the 3'-end towards the 5'-end of the transcript. A detailed view of these potentially mRNA-degradation associated clusters is shown in
C $1, \# 6$

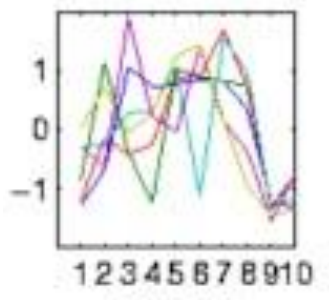

C $5, \# 5$

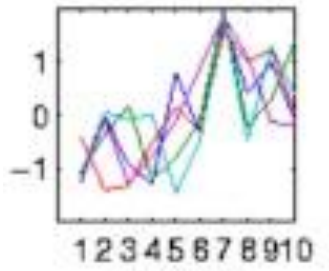

C $9 . \# 6$

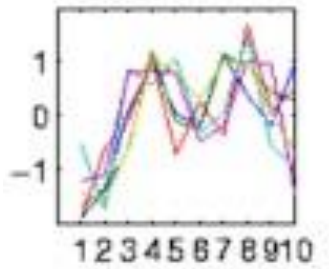

C 13,4

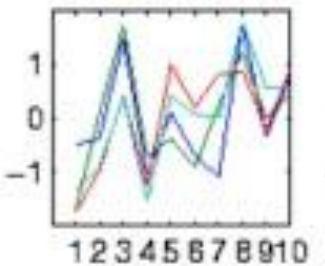

$\mathrm{C} 17, \# 5$

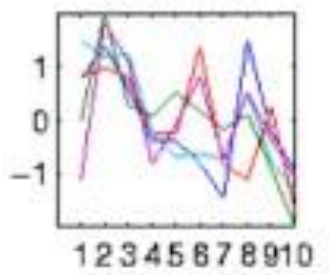

C 2, \#5

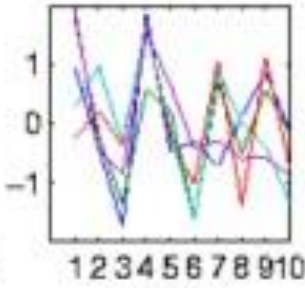

C $6, \# 4$

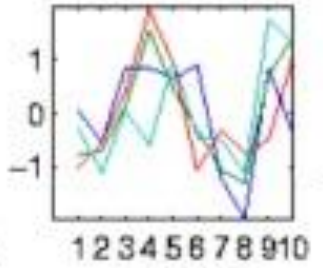

C $10, \# 3$

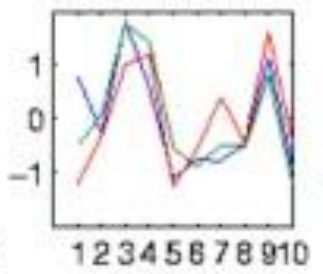

C $14, \# 5$

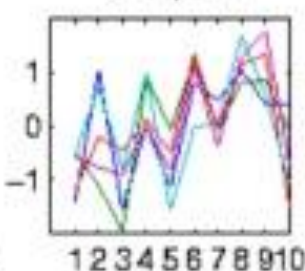

C $18, \# 3$

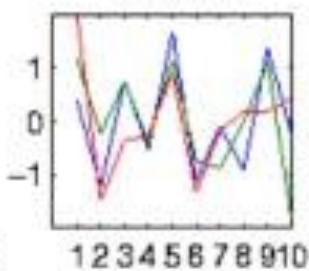

There are other clusters present, which show patterns that do not indicate a specific direction of degradation. It is therefore possible that degradation mechanisms other than the directional processes play a role in Nostoc PCC 7120 as well. However, these patterns are not very prominent in the data. There are two possible reasons for this. Firstly, genes that pass the filtering steps have relatively short transcripts. If degradation is a fast process, most transcripts will already be in a pretty degraded state and directional patterns will not be visible in the data. Secondly, effects other than degradation obscure the degradation signal in the data. Genes were filtered to have little correlation with the GC-contents of their probes, but other effects influencing the hybridization strength of the probe-target complex and their contribution to the expression patterns remain to be identified.
C $3, \# 4$

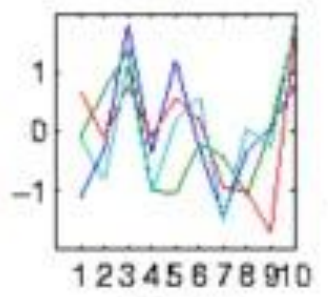

C 7, \#3

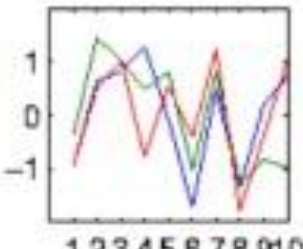

12345878910

$\mathrm{C} 11, \# 4$

1234567890 $\mathrm{C} 15, \# 3$

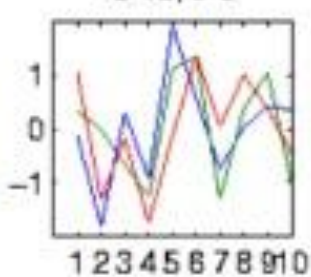

1234567890

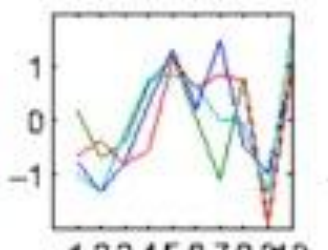

$\mathrm{C} 4, \pm 3$

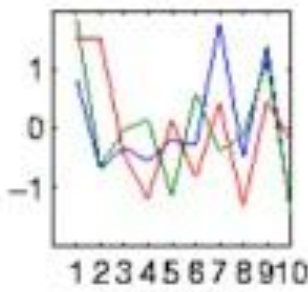

$\mathrm{C} 8, \# 8$

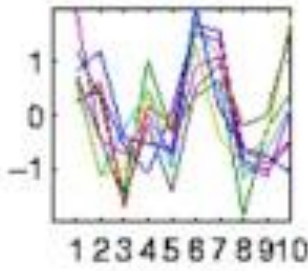

C 12, \#6

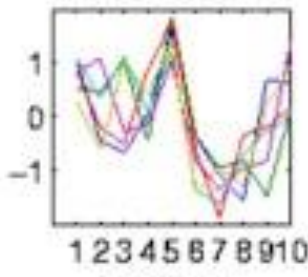

C $16, \# 6$

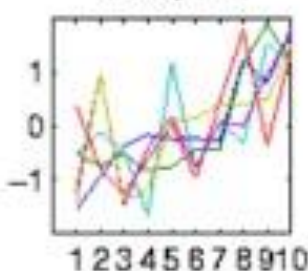

Fig. 8. Resulting Clusters of Fuzzy K-Means Clustering - Clusters C5, C9, C14, and C16 hint at a degradation mechanism progressing from the 5'- to the 3'-end of the transcript. Cluster C17 points to a degradation process in the opposite direction. 


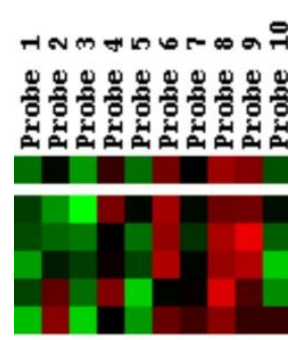

Cluster 14

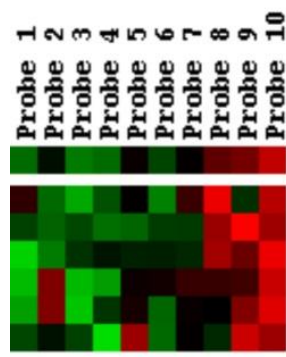

Cluster 16

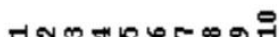

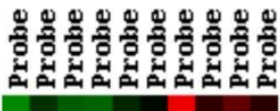

'al12319

'alr7530'

'al14148

'alr4251'

'all014?'

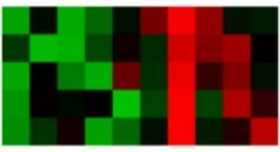

'alr7017'

'alr3758'

al17053'

alr4065

al17510

\section{Cluster 5}

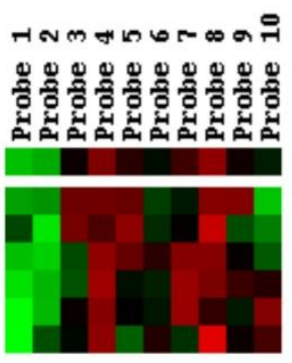

Cluster 9

'al10376'

'allo349'

'al10334

'alr7253'

'all7002'

'al10398'

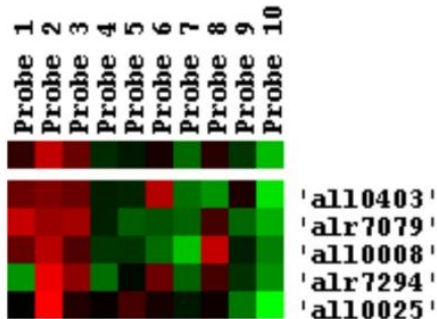

Cluster 17

Fig. 9. Fuzzy K-Means Clustering - Detailed view of the clusters that are potentially associated with mRNA-degradation.

\subsubsection{Hierarchical Clustering}

The results of the hierarchical clustering are depicted in Fig. 10.
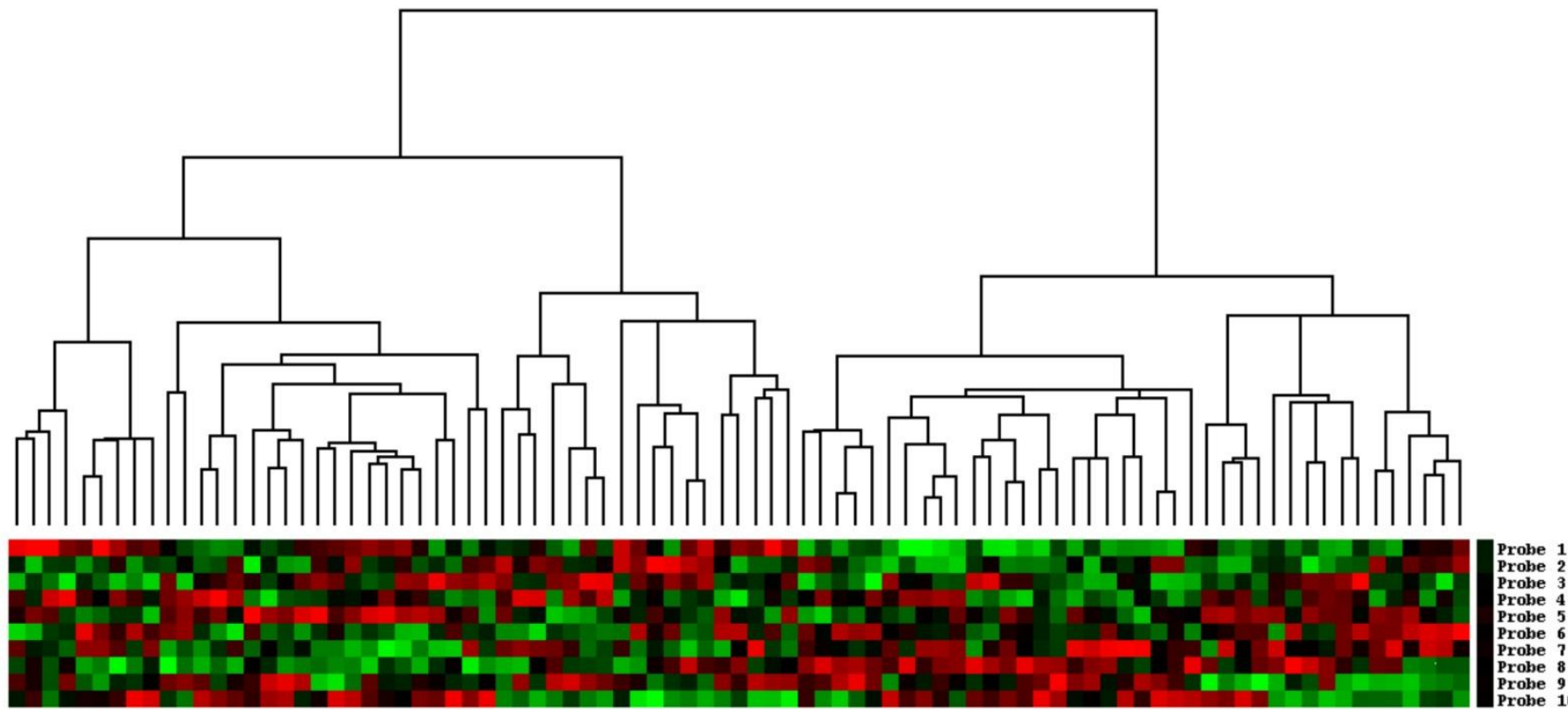

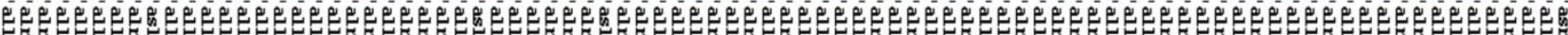

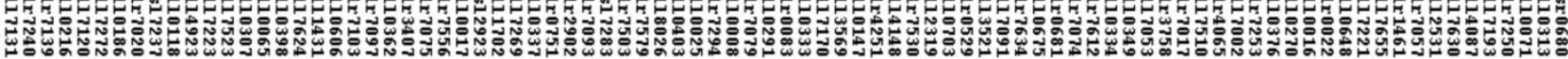
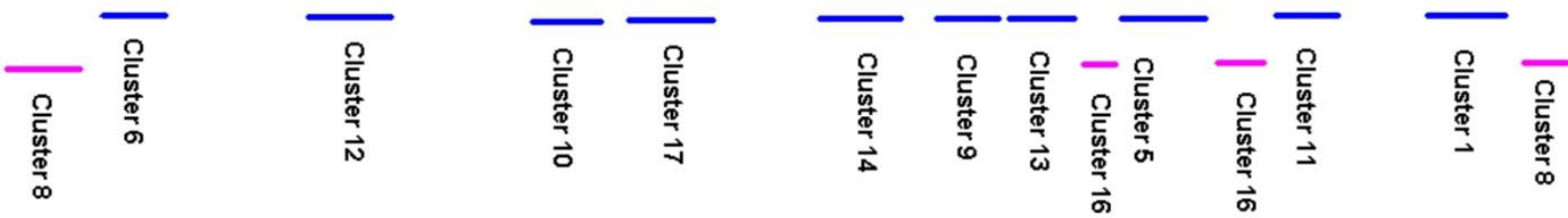

Fig. 10. Hierarchical Clustering - Clusters also found by fuzzy k-means are marked in blue. Pink markers indicate fuzzy k-means clusters that were split by the hierarchical method.

Clusters from the fuzzy k-means clustering are marked. The hierarchical clustering reveals no dominant structures in the data. However, it shows some overlap with the clusters produced by fuzzy k-means. Some of the fuzzy clusters are also found by the hierarchical clustering, some are separated and some are not found. Generally speaking, the hierarchical clustering does not reveal much structure, which is not 
unexpected because all patterns in the data are rather subtle and probably overlayed by noise.

\section{Conclusion}

The goal of the work presented here was to identify different mRNA-degradation patterns from DNA-microarray based gene-expression data. We expected to see at least 4 different degradation patterns: from $5^{\prime} \rightarrow 3^{\prime}, \quad 3^{\prime} \rightarrow 5^{\prime}$, and simultaneously from both ends resulting from exonucleases; and random patterns resulting from the action of endonucleases. Thus, the number of expected clusters when clustering all expression data was greater than 4 (transcripts showing no degradation where excluded from data analysis). Since gene-expression data are very noisy, we increased the number of expected clusters to 18 for fuzzy k-means clustering.

To our surprise, we did not see a big difference between hierarchical and fuzzy k-means clustering (Fig.10). Thus, we restrict ourselves to hierarchical clustering because it does not require specification of the number of expected clusters.

Detailed analysis of our clustering results suggest that several different mRNA-degradation pathways work in concert. Furthermore, we conclude that at least some of the pathways are transcript specific. This requires the recognition of the transcript by components of the degradation machinery. Consequently, we initiated a search for common sequence and structure patterns in each individual cluster.

\section{Acknowledgments}

We like to thank Rikard Axelsson for cell growth and RNA-purification, Michael Baum and Nicole Rittner for performing the DNA-microarray experiments, Long Li for data processing, and Ralf Müller and Alexander Schönhuth for valuable discussion. Furthermore, we like to thank two anonymous reviewers for helpful comment that helped improving the manuscript.

\section{References}

Axelsson, R. and Lindblad, P. (2002), "Transcriptional regulation of Nostoc hydrogenases: effects of oxygen, hydrogen, and nickel" Appl Environ Microbiol, 68(1):444-7. http://dx.doi.org/10.1128/AEM.68.1.444447.2002

Baum, M., Bielau, S., Rittner, N., Schmid, K., Eggelbusch, K., Dahms, M., Schlauersbach, A., Tahedl, H., Beier, M., Güimil, R., Scheffler, M., Hermann, C., Funk, J.-M., Wixmerten, A., Rebscher, H., Hönig, M., Andreae, C., Büchner, D., Moschel, E., Glathe, A., Jäger, E., Thom, M., Greil, A., Bestvater, F., Obermeier, F., Burgmaier, J., Thome, K., Weichert, S., Hein, S., Binnewies, T., Foitzik, V., Müller, M., Stähler, C. F., and Stähler, P. F. (2003), "Validation of a novel, fully integrated and flexible microarray benchtop facility for gene expression profiling" Nucleic Acids Res, 31(23):e151. http://dx.doi.org/10.1093/nar/gng151

Beier, M. and Hoheisel, J. D. (2000), "Production by quantitative photolithographic synthesis of individually quality checked DNA microarrays" Nucleic Acids Res, 28(4):E11. http://dx.doi.org/10.1093/nar/28.4.e11

Carpousis, A., Vanzo, N., and Raynal, L. (1999), "mRNA degradation. A tale of poly(A) and multiprotein machines" Trends Genet, 15(1):24-8. http://dx.doi.org/10.1016/S0168-9525(98)01627-8

Cheng, Z.-F. and Deutscher, M. (2005), "An important role for RNase R in mRNA decay" Mol Cell, $17(2): 313-8$. http://dx.doi.org/10.1016/j.molcel.2004.11.048

Donovan, W. and Kushner, S. (1986), "Polynucleotide phosphorylase and ribonuclease II are required for cell viability and mRNA turnover in Escherichia coli K-12" Proc Natl Acad Sci USA, 83(1):120-4. http://dx.doi.org/10.1073/pnas.83.1.120

Eberwine, J., Yeh, H., Miyashiro, K., Cao, Y., Nair, S., Finnell, R., Zettel, M., and Coleman, P. (1992), "Analysis of gene expression in single live neurons" Proc Natl Acad Sci USA, 89(7):3010-4. http://dx.doi.org/10.1073/pnas.89.7.3010
Eisen, M., Spellman, P., Brown, P., and Botstein, D. (1998), "Cluster analysis and display of genome-wide expression patterns" Proc Natl Acad Sci USA, 95:14863-14868. http://dx.doi.org/10.1073/pnas.95.25.14863

Garneau, N., Wilusz, J., and Wilusz, C. (2007), "The highways and byways of mRNA decay" Nature reviews Molecular cell biology, 8(2):113-126. http://dx.doi.org/10.1038/nrm2104

Gasch, A. and Eisen, M. (2002), "Exploring the conditional coregulation of yeast gene expression through fuzzy k-means clustering" Genome Biology, 3(11). http://dx.doi.org/10.1186/gb-2002-3-11-research0059

Güimil, R., Beier, M., Scheffler, M., Rebscher, H., Funk, J., Wixmerten, A., Baum, M., Hermann, C., Tahedl, H., Moschel, E., Obermeier, F., Sommer, I., Büchner, D., Viehweger, R., Burgmaier, J., Stähler, C., Müller, M., and Stähler, P. (2003), "Geniom technology-the benchtop array facility" Nucleosides Nucleotides Nucleic Acids, 22(5-8):1721-3. http://dx.doi.org/10.1081/NCN-120023122

Hansel, A., Axelsson, R., Lindberg, P., Troshina, O., Wünschiers, R., and Lindblad, P. (2001), "Cloning and characterisation of a hyp gene cluster in the filamentous cyanobacterium Nostoc sp. strain PCC 73102" FEMS Microbiol Lett, 201(1):59-64. http://dx.doi.org/10.1111/j.15746968.2001.tb10733.x

Hasan, A., Stengele, K.-P., Giegrich, H., Cornwell, P., Sham, K., Sachleben, R., Pfleiderer, W., and Foote, S. (1997), "Photolabile protecting groups for nucleotides: synthesis and photodeprotection rates" Tetrahedron, 53:4247-4264. http://dx.doi.org/10.1016/S0040-4020(97)00154-3

Houseley, J. and Tollervey, D. (2009), "The many pathways of RNA degradation" Cell, http://dx.doi.org/10.1016/j.cell.2009.01.019

Kaberdin, V., Singh, D., and Lin-Chao, S. (2011), "Composition and conservation of the mRNA-degrading machinery in bacteria" Journal of biomedical science, 18:23. http://dx.doi.org/10.1186/1423-0127-18-23

Kristoffersen, S., Haase, C., Weil, M., Passalacqua, K., Niazi, F., Hutchison, S., Desany, B., Kolstø, A.-B., Tourasse, N., Read, T., and Økstad, O (2012), "Global mRNA decay analysis at single nucleotide resolution reveals segmental and positional degradation patterns in a Gram-positive bacterium" Genome Biology, 13(4):R30. http://dx.doi.org/10.1186/gb2012-13-4-r30

Kruse, R., Klawonn, F., and Höppner, F. (1999), Fuzzy Cluster Analysis. Wiley \& Sons.

Lackner, D. and Bähler, J. (2008), "Translational control of gene expression from transcripts to transcriptomes" International Review of Cell and Molecular Biology, 271:199-251. http://dx.doi.org/10.1016/S19376448(08)01205-7

Lockhart, D., Dong, H., Byrne, M., Follettie, M. T., Gallo, M., Chee, M., Mittmann, M., Wang, C., Kobayashi, M., Horton, H., and Brown, E. (1996), "Expression monitoring by hybridization to high-density oligonucleotide arrays" Nat Biotechnol, 14(13):1675-80. http://dx.doi.org/10.1038/nbt1296-1675

Mackie, G. (1998), "Ribonuclease E is a 5'-end-dependent endonuclease" Nature, 395(6703):720-3. http://dx.doi.org/10.1038/27246

Maniatis, T., Fritch, E., and Sambrook, J. (1982), "Synthesis and cloning of cDNA" In Molecular cloning, pages 212-246. Cold Spring Harbor Laboratory.

Nierlich, D. and Murakawa, G. (1996), "The decay of bacterial messenger RNA" Prog Nucleic Acid Res Mol Biol, 52:153-216. http://dx.doi.org/10.1016/S0079-6603(08)60967-8

Rule, R., Pozhitkov, A., and Noble, P. (2009), "Use of hidden correlations in short oligonucleotide array data are insufficient for accurate quantification of nucleic acid targets in complex target mixtures" Journal of microbiological methods, http://dx.doi.org/10.1016/j.mimet.2008.10.011

Selinger, D., Saxena, R. M., Cheung, K., Church, G., and Rosenow, C. (2003), "Global RNA half-life analysis in Escherichia coli reveals positional patterns of transcript degradation" Genome Res, 13(2):216-23. http://dx.doi.org/10.1101/gr.912603

Singh-Gasson, S., Green, R., Yue, Y., Nelson, C., Blattner, F., Sussman, M., and Cerrina, F. (1999), "Maskless fabrication of light-directed oligonucleotide microarrays using a digital micromirror array" Nat Biotechnol, 17(10):974-8. http://dx.doi.org/10.1038/13664

Zhou, Y. and Abagyan, R. (2002), "Match-only integral distribution (MOID) algorithm for high-density oligonucleotide array analysis" BMC Bioinformatics, 3(1):3. http://dx.doi.org/10.1186/1471-2105-3-3 